\title{
Connecting Native Students to STEM Research Using Virtual Archaeology
}

\section{A Case Study from the Water Heritage Anthropological Project}

\author{
Molly Boeka Cannon •, Anna S. Cohen ๑, and Kelly N. Jimenez
}

\section{ABSTRACT}

Universities struggle to provide meaningful education and mentorship to Native American students, especially in STEM fields such as archaeology and geography. The Native American Summer Mentorship Program (NASMP) at Utah State University is designed to address Native student retention and representation, and it fosters collaboration between mentors and mentees. In spring 2020, as university instruction went online due to the COVID-19 pandemic, NASMP mentors were faced with adapting hands-on activities and face-to-face interaction to an online format. Using our Water Heritage Anthropological Project as a case study, we show how virtual archaeological, archival, spatial, and anthropological labs can be adapted for online delivery. This approach may be especially useful for reaching students in rural settings but also for engaging students in virtual or remote research in the field sciences.

Keywords: education, virtual research, mentorship, Native American students, water heritage

Una dificultad mayor de las Universidades es ofrecer una educación y tutoría de valor a los estudiantes nativos americanos, especialmente en los campos de tipo STEM como arqueología y geografía. El Native American Summer Mentorship Program (NASMP) ofrecido por la Utah State University fue diseñado para valorar la retención y la representación de estudiantes nativos, así como para promover la colaboración entre mentores y mentoreados. Sin embargo, durante la primavera del 2020, cuando la instrucción universitaria transicionó en línea en relación con la pandemia de COVID-19, los mentores del NASMP se enfrentaron a la adaptación de actividades prácticas e interacciones en persona a un formato en línea. Utilizamos el Water Heritage Anthropological Project como estudio de caso para demostrar cómo laboratorios arqueológicos virtuales, de archivo, espaciales y antropológicos pueden adaptarse a actividades educacionales en línea. Tal acercamiento puede volverse especialmente útil en el caso de poblaciones estudiantiles rurales, así como para involucrar más adelante los estudiantes en actividades de investigación virtual o remota en las ciencias "de campo".

Palabras clave: educación, investigación virtual, tutoría, estudiantes nativos americanos, patrimonia del agua

Mentorship and hands-on activities are critical for engaging Native American students in postsecondary education and for providing these students with tools for a successful university experience (Keith et al. 2016; Shotton et al. 2007). When university instruction went online in March 2020 due to the COVID-19 pandemic, laboratories and experiential-learning instructors encountered an extra set of issues. Should we cancel our hands-on activities or adapt to an often-intangible online format? What about mentorship programs, designed to match first-generation and Native American students with mentors and the broader resources of the university? How can such programs be transferred online without losing the face-to-face interaction critical for student success?

Many university instructors quickly adapted to the pandemic by incorporating online teaching in the spring 2020 semester. Utah
State University (USU) is already familiar with distance learning -its first online course was offered 25 years ago (USU Online 2020). Today, there are more than 500 courses offered and 60 degree and certificate programs available online, including an anthropology minor. Yet, there was a new challenge for an important summer program - the Native American Summer Mentorship Program (NASMP)—which is typically offered in person at the main Logan campus. In existence since 2014, the NASMP provides an opportunity for Native American students enrolled at the USU statewide campuses to spend a month at the Logan campus. Professors create weeklong labs for these students in the STEM fields. Designed to help the students experience life in Logan, a college city that is larger than many communities outside of the Salt Lake area, the NASMP introduces students to future mentors for forthcoming semesters.

\section{Advances in Archaeological Practice 9(2), 2021, pp. 175-185}

Copyright (1) The Author(s), 2021. Published by Cambridge University Press on behalf of Society for American Archaeology. This is an Open Access article, distributed under the terms of the Creative Commons Attribution-NonCommercial-NoDerivatives licence (http:// creativecommons.org/licenses/by-nc-nd/4.0/), which permits non-commercial re-use, distribution, and reproduction in any medium, provided the original work is unaltered and is properly cited. The written permission of Cambridge University Press must be obtained for commercial re-use or in order to create a derivative work.

DOI:10.1017/aap.2021.2 


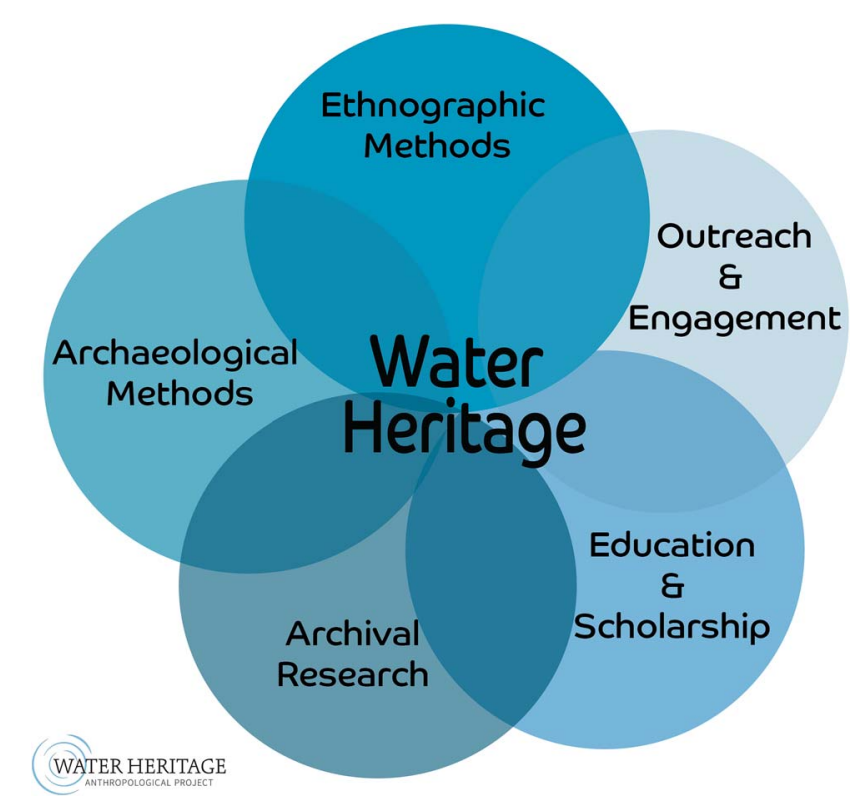

FIGURE 1. Venn diagram of the Water Heritage Research Methods.

In this article, we illustrate our approach to the 2020 virtual NASMP through our Water Heritage Anthropological Project (WHAP), a multidisciplinary project that looks at water features through the lens of archaeological, archival, geographical, and anthropological data (Figure 1). The WHAP team members who participated in the virtual lab include principal investigators Molly Boeka Cannon and Anna Cohen along with graduate student assistant Kelly Jimenez. We were joined by two undergraduate students who are completing their associate's degrees at USU Blanding and who are both members of the Navajo Nation. We show that the virtual WHAP is a way to integrate students who are located far away from a researcher's laboratory and campus. This is an especially important adaptation for anthropology and archaeology, fields that are built around face-to-face interaction and material culture. Here, we show how labs can be adapted to an online format and demonstrate that they will be vital for future research-teaching techniques in the coming months-or even years. This approach is particularly useful for campuses with statewide locations and online degree programs for engaging students in virtual or remote research.

\section{MENTORING NATIVE STUDENTS THROUGH RESEARCH}

Colleges and universities struggle to provide meaningful education that ensures Native student retention and representation on postsecondary campuses (Adelman et al. 2013; Guillory and Wolverton 2008). The NASMP serves undergraduate students with the goal of providing research mentorship opportunities to increase Native American student retention and representation at four-year universities and to foster collaboration between mentors and Native mentees. The majority of participants in the program are enrolled at the USU Blanding campus in southern Utah. The program focuses on STEM laboratories and fosters partnerships with more than 70 labs on the USU Logan campus. The NASMP offers success to its students: more than $60 \%$ of students who participated in the program have continued their education in a four-year school. Mentorship, via the NASMP and other similar programs, is widely recognized (Crisp and Cruz 2009; National Academies of Sciences Engineering, and Medicine 2019) for stressing a personal connection between faculty, researchers, and students by placing only two students each week in a laboratory. This spotlights the intimate research experience and provides a chance for the mentors and the mentees to share and learn from one another, creating both a knowledge and an emotional support network that aims to further the NASMP participants' academic success. It was imperative that researchers continue this tradition of success in 2020, given that our Native students and their communities continue to be disproportionally disadvantaged by the pandemic (Gamble et al. 2020; Navajo Nation COVID-19 Dashboard 2020).

STEM fields and archaeology can make important contributions to rural communities, including Native students, by utilizing online educational tools. Recent studies show that web-based and online applications in STEM education can be used effectively to teach rural students' frameworks for problem solving and logical thinking (Kefalis and Drigas 2019; National Academies of Sciences, Engineering, and Medicine 2018). The ability to provide access for remote or distance research opportunities increases student retention in the STEM fields (Rogers and Sun 2018). Research can also benefit communities outside the academy. For example, archaeologists have only recently begun to use so-called citizen science approaches to harness remote data-collection efforts across multiple populations (Lin et al. 2014; Porcello and Hsi 2013; Yates 2018). Students can contribute to this work too-for example, there was a study that demonstrates how French university students can identify features in lidar products (Forest et al. 2020). With appropriate internet access, rural residents could similarly make important contributions to archaeological citizen-science approaches.

A key goal for our involvement with the NASMP is to connect Native students to STEM labs_labs that are sometimes unfamiliar to Native students - with a focus on archaeological research. Participating in the NASMP provides benefits on multiple levels. Mentees gain access to STEM education, knowledge, and transferable research skills through their participation in the monthlong program with various labs. Mentors and the research team gain exposure to diverse perspectives and an opportunity to foster cultural competency and create inclusive research teams. The institution sees increased student success and retention rates, growth in impactful research programs, and increased Native student participation in STEM fields across colleges. Finally, our partnership with the NASMP is a small step toward including Native voices in archaeological research. A growing body of work in archaeology recognizes long-standing failures to fully engage Native peoples in research and systemic issues that marginalize Native communities (Atalay 2012, 2019; Smith 2012). Our approach to the NASMP summer labs includes open dialogue between mentors and mentees, as well as a commitment to engagement in the research process-one in which Native students have the ability to contribute meaningfully to the research goals and direct their research efforts based on their interests and lived experiences. The USU Museum of Anthropology undertook previous face-to-face versions of the NASMP from 2016 to 2019, where 
students contributed to archaeological documentation of the Transcontinental Railroad in western Utah. During the earlier labs, Native students participated in fieldwork, archival research, material culture documentation, and outreach. Our challenge this year was to create a virtual space where Native students could participate in STEM education and research that also met student needs for accessibility, comfort, and engagement. Although the data collection and instruction delivery were different, the learning objectives persisted (Figure 2).

\section{VIRTUAL NASMP AND WATER HERITAGE LAB}

The WHAP engages STEM research and education across a number of dimensions, including 3D visualizations and built environment studies, and especially through spatial-temporal interpretations of past behaviors and landscapes. Much of the WHAP research takes place in a traditional laboratory space on campus, a lab filled with undergraduate and graduate students engaged in data collection, analysis, and discussion with mentors. Our initial plan was to offer this opportunity to the two NASMP mentees using the facilities at the Logan campus, but remote instruction required a redesign of our weeklong lab. Consequently, we met Monday through Friday virtually using Zoom, with labs running from 9:00 a.m. to 4:00 p.m. each day. Each remote lab built on one another and explored the five WHAP research dimensions (Figure 3). We divided the day into three segments: from 9:00 to 11:00 a.m., we held discussions and instructions on the day's topic; midday consisted of independent work sessions during which students completed research tasks; and at 3:00 p.m., we regrouped via Zoom to discuss outcomes.

Morning discussions began with a prompt, such as a question, an object, or the sharing of a personal anecdote. We also included a more in-depth discussion centered on a reading (e.g., Hein et al. 2020), which provided foundational information that we later expanded on in our lab activities. Each reading assigned during the week included a note-taking template that the students could use to guide their consumption of the material. The template put our learning objectives into practice by asking the students to respond to questions that prompted them to summarize the material as well as complete evaluative and propositional tasks (Figure 4). Following our discussion, we introduced the lab activity before breaking for the midday, independent work session. Lab assignments provided step-by-step instructions for completing the learning objective (Figure 5). Mentors remained available (via text, phone, e-mail, or Zoom) to answer questions. Mentors and students would regroup at 3:00 p.m. to discuss the lab activities. These sessions were minimally structured and served as a debriefing period during which students could ask additional questions and share their work. Our workflow included using proprietary software and virtual classrooms such as Zoom, Microsoft Office, ESRI ArcGIS, Box, and Canvas. The teaching approaches and lab activities, however, could easily be migrated to open-source options (Figure 6).

\section{Day 1: Scholarship Lab}

We discussed defining and exploring water heritage for each of us as individuals and as scholars. We agreed that water heritage scholarship affords an opportunity to understand, fundamentally, how humans connect with resource management, landscape construction, and environment. All of us have a connection with water and a deep attachment to its significance in our everyday life. This is particularly germane in the arid U.S. Mountain West, where water access has long been a major concern (e.g., Dixon 2014; Miller 2007; Simms et al. 2020). Although our learning objectives included basic skills related to knowledge building (such as repeat tasks, defining, and summarizing), principally, we wished to share the research process with mentees, and we wanted to move quickly to more advanced knowledge-building tasks such as manipulating data, developing interpretations, and drawing comparisons.

Each activity for this first day introduced new vocabulary and concepts, asked students to connect to these concepts personally, and explored the concepts through other scholarship and the lesson. The first assignment mentored the students through a reading exercise to extract main points, assisted them in developing their own evaluation of concepts, and prompted them to consider how the concepts would be met by their own communities (Figure 4). The accompanying archaeological task included data entry and manipulation. Students were presented with a demonstration on how to enter data into a Microsoft Excel spreadsheet. They were provided with an Excel document through Canvas that they could update with previously collected archival information. The data-entry exercise was an opportunity to teach skills related to transposing archival information to data, data organization, categories of data (text, numeric), and data visualization with charts and graphs.

\section{Day 2: Ethnography Lab}

We initiated our group discussion by bringing or sharing stories of objects that hold meaning for us. For example, one mentor presented a paper recipe card and a story about family heirlooms (baking dishes) and traditions, whereas a student shared a story about handmade beaded earrings that her mother had given to her. This exercise facilitated a discussion about the tangible and intangible aspects of heritage, linking objects to personal histories and memory (Brown et al. 2016; Tilley et al. 2006), and set the foundation for a larger discussion on using interviews and ethnographic methods for archaeological and historic inquiry. We also considered the use of digital tools such as Zoom to conduct interviews and the ways they may be useful or difficult to implement in settings such as the Navajo Nation (Janghorban et al. 2014; see also Lupton 2020).

We then shared our interview protocol, demonstrating how to set up a virtual interview using Zoom, follow the interview protocol, record, and collect interview data. Students completed an ethnographic interview with one another on the meaning of water heritage using the interview protocol on their own. We reconvened to discuss the process and compare and contrast their findings with the WHAP teams' interview dataset. Two themes emerged from the students' interviews that differed from the existing WHAP interview dataset: sacredness and environmental health. Water was viewed as explicitly sacred by the students. Although many of the study participants mentioned the importance of water, even commenting that "water is life," no study participant described water as sacred. One mentee mentioned that the San Juan River is a sacred body used in ceremonies but 


\section{Remember \& Recall}

- Repeat mapping tasks

- List artifact classes

- Define and recall archaeological terms

\section{Understand \& Explain}

- Document material culture

- Summarize main points

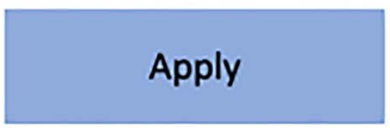

- Collect archaeological data

- Collect archival information

- Manipulate data

- Interpret datasets

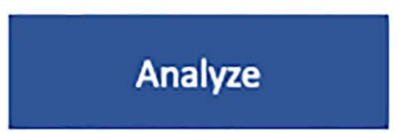

- Compare archaeological dataset

- Quantify differences

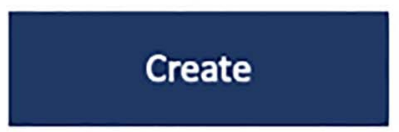

- Communicate findings

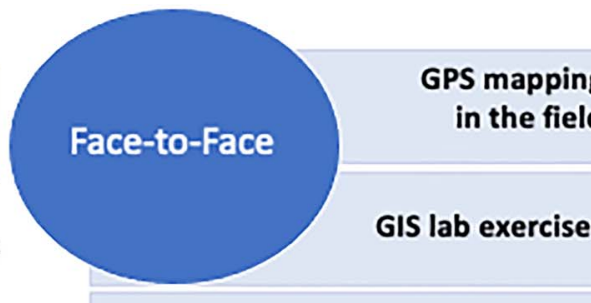

Lecture/Discussion sessions

Identify surface artifacts in the field

Reading discussions

Map a feature

Document surface assemblages

Create spatial datasets from field data

Process imagery from geophysical survey

Interpret maps and images

Use GIS to make feature comparisons

Compare results from fieldwork

Create a report of week's research

Create a poster of week's experience

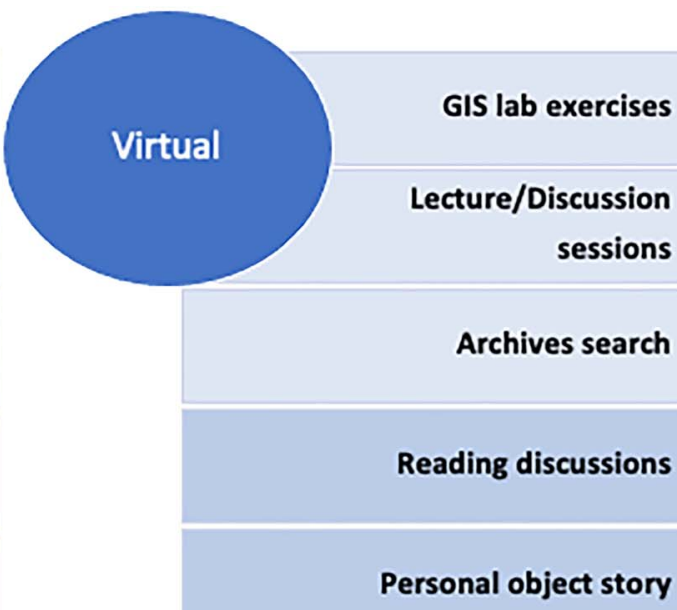

Create spatial data from archive datasets

Collect and summarize ethnograpic interview data

Assemble a map from spatial data

Assemble archvial data

Discuss comparisons in ethnographic interviews

Use ArcGIS online to make quantatitve assessments

Create archival report

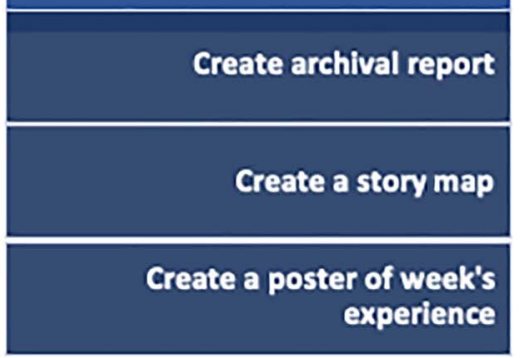

FIGURE 2. Learning objectives and archaeological tasks migration from previous face-to-face labs to the virtual lab, an adaptation of Bloom's Taxonomy into archaeological pedagogy (Bloom 1956; Colaninno 2019; Krathwohl 2002).

that, due to recent environmental impacts in the watershed, the river cannot support water for consumption. Instead, residents in her community rely on bottled water for drinking and surface water for bathing and livestock. The ethnography lab created an opportunity to cover ethnographic methods and build vocabulary, apply the interviewing process, and analyze interview data. The open discussion gave the mentees the opportunity to share knowledge about water resources and challenges that their communities face every day regarding a lack of access to a safe water supply.

\section{Day 3: Geospatial Analysis and Visualizations Lab}

The third lab covered the WHAP's use of ESRI's ArcGIS Online platform for geospatial data management, sharing, and visualizations. The mentors developed a lab for the students to learn the basics of geographic information systems (GIS). We began the day with a tour of ArcGIS Online and a demonstration on how to work with the project geodatabase. ArcGIS Online affords access to basic and advanced geospatial analyses without the need to 


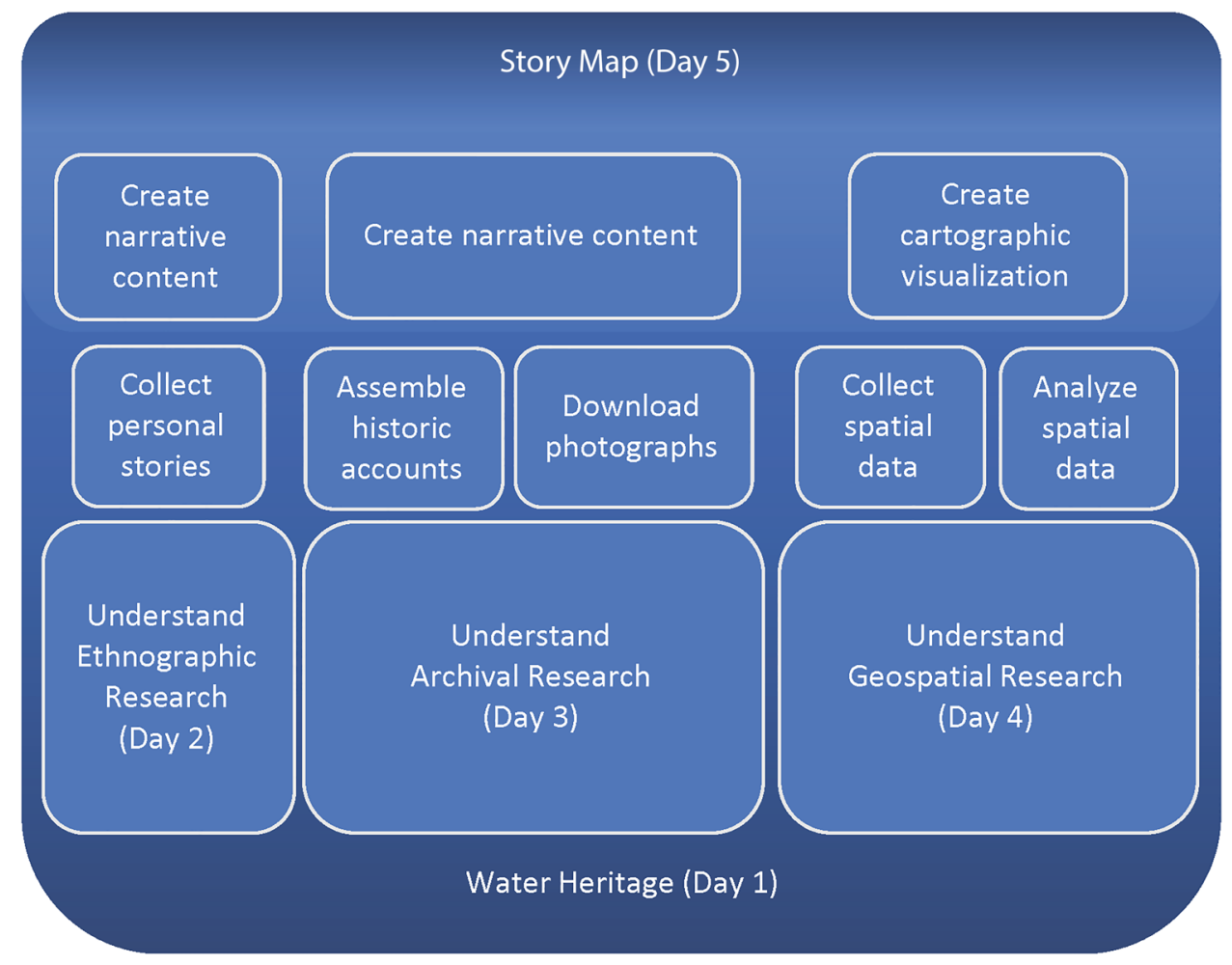

FIGURE 3. Illustration of scaffolding of content from daily labs.

install software or house spatial datasets on a personal computer. ArcGIS Online permits remote access to data and software, and it is apposite for collaborative work by remote research teams and distanced teaching. Students followed the step-by-step exercises during the independent work session (Figure 7) and performed basic GIS and cartographic tasks—such as labeling, symbolizing, and map production-and more advanced tasks using quantitative analyses. When we reconvened during the afternoon session, the mentees shared their maps, and we discussed the challenges of integrating GIS research into water heritage studies. The mentees expressed an interest in geospatial analysis and its connection to landscape research.

\section{Day 4: Archival Research Lab}

For some time, scholars have noted how archival data can complement the behaviors observed in the archaeological record (Hanson and Oltean 2013; Little 1991). The archival lab introduced mentees to archives and their use in historical archaeology. We relied on library and research guides developed by subject librarians with USU Special Collections to share databases, primary sources, and research methods for archival scholarship (Duncan 2020). With a virtual lecture and tour of a digital archive, we introduced archives and their role in research. The tour included instructions on how to use library guides and how to find aids for archive searches. Students completed a guided research assignment using the Bear River Watershed Digital Collection curated at the USU Digital History Collections during the independent work session. We designed the assignment so that students would explore digital archives relevant to the project, practice searching for specific content-including photographs, first person accounts, and newspaper articles-download and organize content in cloud storage (Box), and produce a write-up of their research. Because this was the first major writing task for the week, we provided an outline for the research write-up, with headings and image placeholders that mentees could use to guide their work. We reconvened to discuss their research findings and assess progress on the write-up, concluding our afternoon discussion by highlighting key research findings that could be incorporated into the final day's outreach activity.

The archives lab was particularly well suited for remote delivery and distanced research, especially for students and researchers in rural settings. Online databases, research guides, and curated digital collections put the library in their home. Fortunately for WHAP, water resources and water heritage are key issues in the West, and a wealth of information can be found in digital formats.

\section{Day 5: Public Outreach Lab}

As a publicly funded project, WHAP envisions outreach as a central tenet, alongside scholarship and teaching. The NASMP virtual lab served as one of our first outreach efforts by introducing students who are not associated with the project to water heritage scholarship. In this final lab, the students applied their knowledge from the previous labs to create a story map using ESRI ArcGIS Online StoryMaps. StoryMaps offer an accessible medium to deliver geospatial information through narrative formats that engage viewers with humanist accounts. Our learning objectives were to share with students the entire research process-knowledge acquisition, data collection and interpretation, analysis, and 


\section{CONNECTING WATER AND}

\section{HERITAGE FOR THE FUTURE}

Hein, C. Henk van Schaik, Diederik Six, Tino Mager, Jan (J. C. A.) Kolen, Maurits Ertsen,

Steffen Nijhuis and Gerdy Verschuure-Stuip.

2020 Introduction: Connecting Water and Heritage for the Future. In Adaptive

Strategies for Water Heritage, pp. 1-18. Springer, Cham, 2020. DOI: 10.1007/978-3-

030-00268-8_1, accessed September 15, 2020.

1. SUMMARY

A. What is main argument presented in this article?

B. How do the authors define and understand 'heritage'?

C. How do water features and systems connect with heritage and identity?

i. SUMMARIZE

1. List two examples from the text that link features with cultural behaviors

D. What is the issue with studying water and cultural heritage separately?

i. Which disciplines tend to study water?

ii. Which disciplines tend to study cultural heritage

iii. Summarize the effect of this approach

E. What can be learned by studying heritage and water together?

2. EVALUATION \& PROPOSITION

A. Can you think of examples from your own culture that link water features to cultural behaviors?

B. Can you identify water management practices that you rely on in your daily life?

C. Can you identify impacts for understanding water heritage in your community?

D. Can you propose projects or activities that might explore water heritage in your region?

E. Can you propose projects or activities that can be developed to share information about water heritage with the public?

FIGURE 4. Note-taking template used in the scholarship lab (Day 1) for Hein and colleagues (2020).

dissemination to the public. We began the day utilizing the note-taking template while watching a presentation by Nina Simon (2014) of the Santa Cruz Museum of Art \& History (MAH), during which she shares observations about material culture as social objects for building community. Our discussions included thinking about water heritage and community and left students with the task of creating a public outreach tool to share their research findings from the week. Although a oneweek lab is insufficient to produce a story map fully, students practiced integrating cursory research and produced a draft story map that the WHAP team could build on for future outreach efforts (Figure 8 ).

\section{WHAT WORKED AND WHAT DID NOT}

Zoom, a virtual visual platform, allowed us to have meaningful discussions, similar to face-to-face settings, and to hear the students' perspectives and experiences about water heritage in their lives. These immediate reactions and comments are sometimes hindered by the formality of written discussion boards used in many online class formats. Zoom offered the opportunity to preserve the quality of discussion achieved in the classroom. In NASMP exit surveys, students also preferred 


\section{Day 3 Geospatial Analysis \& Visualizations Lab}

\section{Definitions:}

Geodatabase: A geodatabase is one way to store GIS information in one large file. These data can be polygons, points, polylines, or raster files. This is a useful way to organize data and helps the transfer and sharing of data across multiple programs and users.

Shapefile: A shapefile is a nontopological format for storing the geometric location and attribute information of geographic features. These data can come in the shape of a single point, a polyline, or a polygon.

Raster Data: A raster file consists of a matrix of cells, or pixels, organized into rows and columns (think of a grid) where each cell contains a value representing information, such as temperature.

Step 3: Spend some time exploring the different parts of the Map Viewer. The sidebar to the left contains the different data within the WHAP geodatabase.

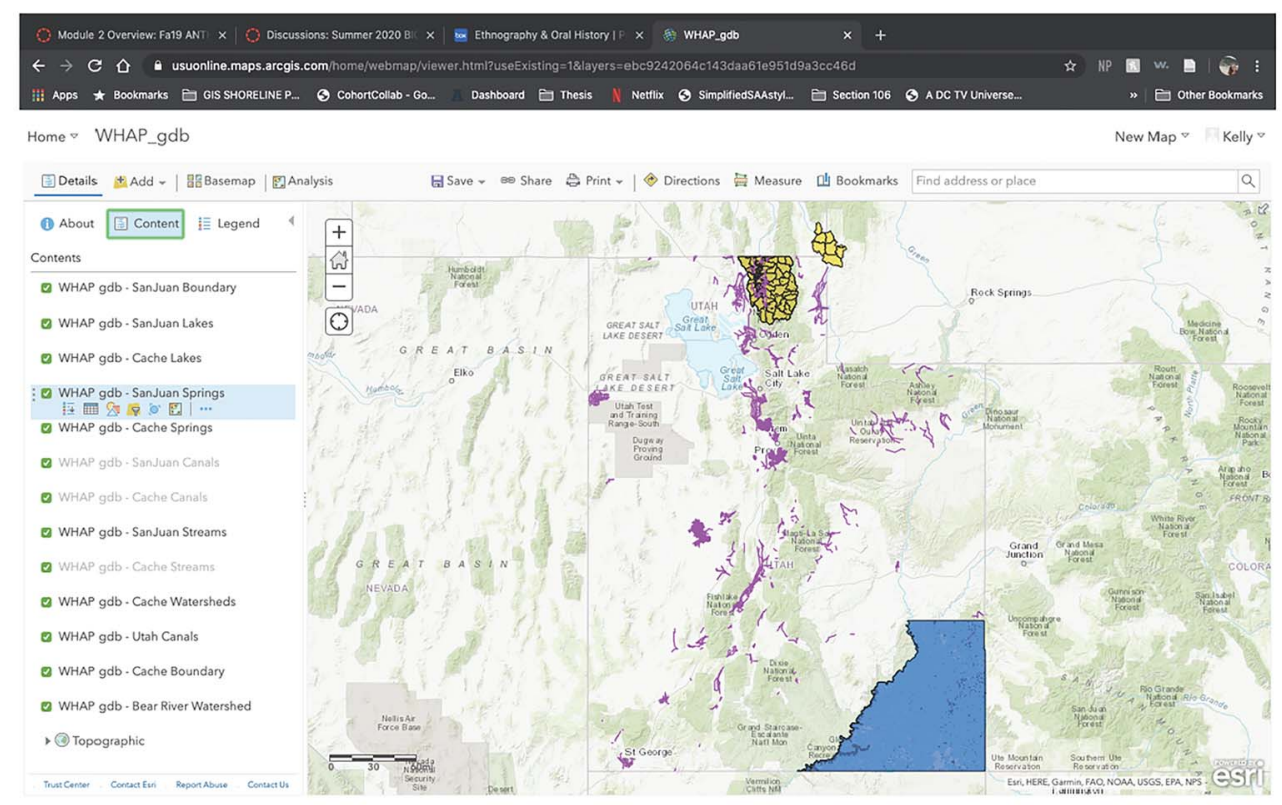

a. Practice turning on and off the different files by clicking the green check next to the file names on the sidebar. As you do this notice how the map changes. Note: Some of the files may be grayed out. This only means that those shapefiles have not "drawn". This will change as you turn other files off and/or zoom into different areas on the map.

b. Zoom in to Cache County by double clicking the county boundary or by clicking the plus sign in the upper left corner of the map screen. Move the map screen around by clicking a dragging in the direction of you choosing. Notice how more data can now be seen in the Map Viewer.

FIGURE 5. An excerpt from the geospatial lab (Day 3) activity, illustrating the step-by-step instruction and vocabulary. 


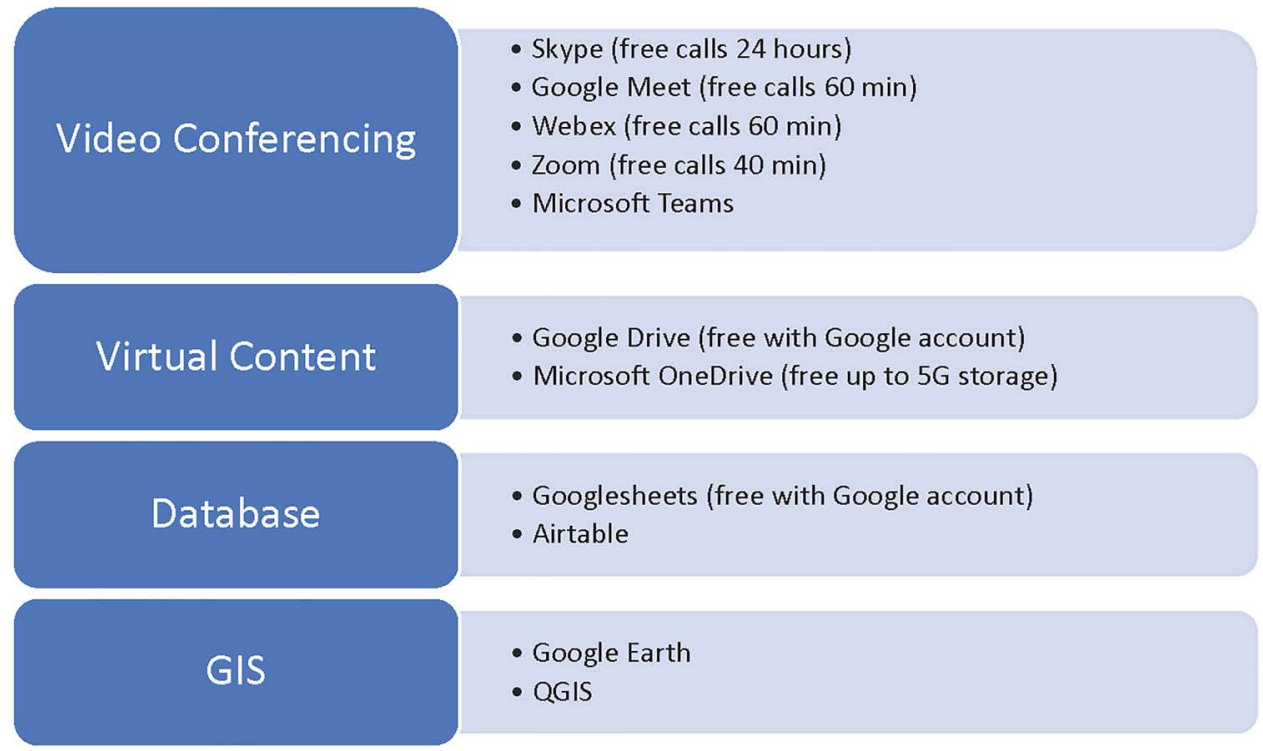

FIGURE 6. Possible open-source alternatives to the software and virtual classroom options used in the NASMP virtual lab.

synchronous video conferencing to asynchronous online engagements.

Our labs illustrate that clear learning objectives, operationalized in easy-to-follow assignments, are foundational for strong mentor-mentee relations (Allan 1996; O'Flaherty et al. 2015; Reddy and Andrade 2010). Well-structured activities such as the daily note-taking template and the ethnography lab on Day 2 proved to be the most successful for developing meaningful virtual discussions. Additionally, when we took time for demonstrations-such as the geospatial lab on Day 3-students completed tasks most proficiently. In exit surveys, mentees mentioned that they preferred activities that explored relevant local issues, that were hands on, and that utilized interactive platforms such as StoryMaps.

Engaging students in discussions can be difficult, however, especially if they are shy or unfamiliar with the content and learning environment. We faced a few challenges keeping students engaged in certain discussions and assignments that warrant mention, and these may be improved in the future using different tactics. For our daily discussions, we offered the mentees the choice of using both video and audio capabilities on Zoom or audio only with their video turned off, with the hope of providing the most comfortable and accessible setting for the students. Most days, the students chose to use audio only, whereas the instructors used both audio and visual capabilities. Although providing students with an environment in which they are comfortable learning is important, the audio-only format placed a barrier between the mentors and mentees and detracted from the informal discussions we had hoped to achieve.

Another challenge for maintaining student engagement lies in the difference between how the NASMP is usually conducted and the remote learning we faced in 2020. In previous years, students lived on the USU Logan main campus, away from home and in the context of the traditional college experience and conveniences. This year, students remained at home and attended the program alongside other personal responsibilities and coursework. This sometimes distracted them from their work efforts for the WHAP lab and prohibited their full commitment to discussions, resulting in unfocused or unfinished products.

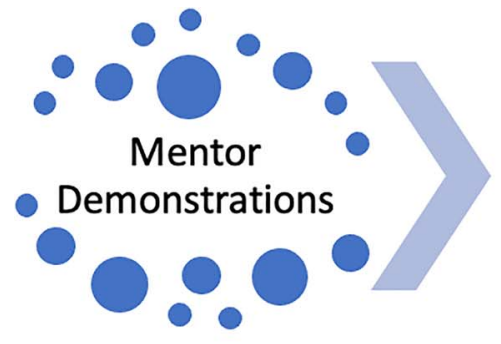

-Lecture - concepts \& vocabulary

-ArcGIS Tour - visual instruction of GIS tasks

\section{Student Replication}
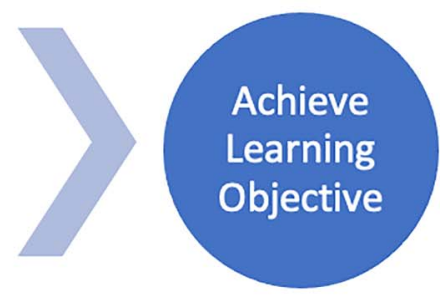
- Guided lessons
- Virtual
Troubleshooting (phone/text/Zoom)

FIGURE 7. Workflow for the geospatial lab (Day 3). 


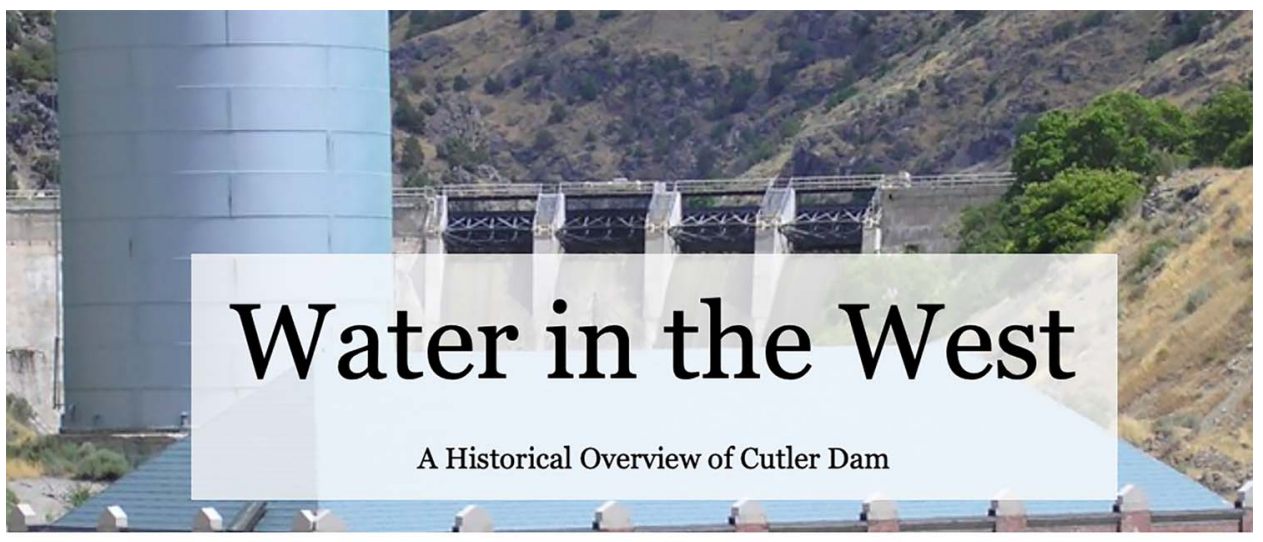

\author{
Welcome to the Water Heritage \\ Anthropological Project at Utah State \\ University.
}

Dive into our Story Map series about how water has been used and manipulated by humans as a

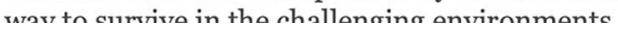

FIGURE 8. First storyboard for "Water in the West," a Water Heritage Anthropological Project story map. For the public outreach lab (Day 5), NASMP students designed their own story maps based on local water-feature research from previous lab activities.

Lack of engagement could also be due to lack of accessibility to needed technology requirements. Proper Wi-Fi speeds, adequate technology, and a dedicated learning environment is necessary to provide the best remote-learning experience. Given that the NASMP students did not have access to the USU main campus, they had to find the most convenient way to participate in the weekly labs. Our mentees often used their smartphones for meetings and assignments that were designed to be carried out on desktop or laptop computers.

\section{KEY TAKEAWAYS FROM THE REMOTE WHAP LAB}

(1) Take time and establish the culture for the lab, including rules of participation. Engagement is critical in any learning environment, and it can be difficult to master in remote settings. Reliable internet is necessary for the virtual format of delivery at all locations. Unstable connections lead to either participation with audio only at best or no participation at all. We found engagement to be optimal when all participants were able to connect with both audio and video streams. But we needed to prepare and deliver the lab under lessthan-ideal situations and at times when video streaming was not possible for all participants. We relied on approaches such as participant callout, round-robin responses, note-taking guides, and material culture prompts. Our lab facilitated learning for only a couple of students and did not need to rely on additional tools. A larger lab or class may wish to develop a protocol for discussions that defines the use of discussion rooms, a dedicated facilitator to monitor participants while the discussant/lecturer shares content, and clear expectations for how to participate using tools (such as "raise hand," polling, and the chat) within the virtual meeting.

(2) Structure contributes to learning outcomes. Keeping the day well scheduled with some time for individualized work fosters independence and agency, but expectations of work must be well articulated. The implemented activity for the archival lab did not meet the expectations we established when we designed the lesson. A potential improvement could be to have students repeat the demonstrated tasks with mentors before moving to independent work sessions. In addition, we recommend that, for future virtual labs, expectations of time per task be provided to students to aid in structuring the independent work as well as emphasizing how that work would be incorporated into the project research. Prior students' contributions from the 2016-2019 labs seemed more apparent to and acknowledged by the mentees. The virtual format produced a distance that we, as mentors, did not fully bridge with respect to our communicating the importance of the 2020 mentees' work for our research.

(3) Scaffolding content and active learning reinforces research concepts. From the onset of the WHAP labs, we wished to share with the mentees all aspects of our project, including data collection, manipulation, analysis, visualization, and outreach. Therefore, it was imperative that the design of the lab and individual daily tasks build upon one another. Each student was assigned a water feature during the geospatial lab (Day 3), and each continued to research, document, and visualize that feature in both the archival lab (Day 4) and the public outreach lab (Day 5). Although condensed, this format follows the overarching trajectory for the WHAP. One mentee (Holliday 2020) recalls of her experience, "We learned how to enter data into a spreadsheet, visualize data, conduct interviews, do archival research, and present our findings to the 
public." Later, she mentioned that her participation in these activities throughout the week shed light on our project objectives: "The project is strongly committed to growing a conservation ethic, and that shared cultural experiences contribute to a sense of place and communal identity." Her statements reflect mastery of the learning objectives that we hoped the mentees would achieve.

(4) Design with accessibility and multiple platforms in mind. Students access digital content from a myriad of devices, including smartphones, laptops, and tablets (Baldwin and Ching 2020). Each device presents an accessibility challenge that must be planned for when designing a remote research environment. Knowing that students may use different devices depending on the task is important when considering how to engage students in the research process. For example, a smartphone may be well suited for video conferencing for meetings and interviews, but it will present challenges for data entry and report generation. Because you may have to work with students who only have access to one type of device, tasks may need to be assigned based on access to technology.

\section{CONCLUSION}

During periods of remote learning-such as the one brought on by the current COVID-19 pandemic-teachers, scholars, and students must adapt to changing conditions. Even though USU has long offered remote learning options, the pandemic presented a new challenge for mentorship and field sciences such as archaeology. The NASMP is a critical resource for Native American students at USU, and although in-person mentorship is preferable, we show that it is possible to use the virtual WHAP labs to connect these students to STEM learning centers. Our example demonstrates that we can offer students research opportunitiesdelivered in a remote format-and continue our mission of a student-centered university with a focus on academics, diversity of thought, and service to the public. The virtual labs that our team developed created a space for mentorship of the two Native student mentees by the research team, connected the students to research in our lab, and fostered a relationship between the students and the Logan campus. The key takeaways provide a road map for refinement for our remote research, which we continue to do with the WHAP team. Our remote research continued with undergraduate anthropology majors and graduate students in archaeology throughout the summer and fall of 2020, during which we have conducted over 15 virtual ethnographic interviews as well as archival research and geospatial analyses. Our weeklong curriculum is provided on the project website for adaptation into other remote teaching and research. Similar initiatives will be important for remote learning contexts, whether for students living in rural settings or for others hoping to participate in anthropological research from afar.

\section{Acknowledgments}

We wish to thank the two USU students who participated in the Native American Summer Mentorship Program and assisted in our virtual research. We thank Elizabeth Simpson, Hannah Wilson, and Megen Kepas for their dedication to the coordination of the NASMP. We thank Marion Forest for checking our abstracts and translations. We are grateful to Utah State University for supporting inclusion initiatives such as the NASMP and encouraging faculty to create diverse research teams. Funding for the Water Heritage Anthropological Project is provided by the Bureau of Reclamation (Award R19AC00171). Finally, we thank the four anonymous reviewers who provided insightful comments for improvement and clarity in the manuscript.

\section{Data Availability Statement}

All materials used in the 2020 remote Water Heritage Anthropological Project labs can be accessed at the project's digital archive: https://digitalcommons.usu.edu/water_heritage/.

\section{REFERENCES CITED}

Adelman, Howard S., Linda Taylor, and Perry Nelson

2013 Native American Students Going to and Staying in Postsecondary Education: An Intervention Perspective. American Indian Culture and Research Journal 37(3):29-56.

Allan, Joanna

1996 Learning Outcomes in Higher Education. Studies in Higher Education 21:93-108.

Atalay, Sonya

2012 Community-Based Archaeology: Research with, by, and for Indigenous and Local Communities. University of California Press, Berkeley.

2019 Can Archaeology Help Decolonize the Way Institutions Think? How Community-Based Research Is Transforming the Archaeology Training Toolbox and Helping to Transform Institutions. Archaeologies 15:514-535.

Baldwin, Sally J., and Yu-Hui Ching

2020 Guidelines for Designing Online Courses for Mobile Devices. TechTrend 64:413-422. DOI:10.1007/s11528-019-00463-6.

Bloom, Benjamin S.

1956 Taxonomy of Educational Objectives: The Classification of Educational Goals - Handbook 1, Cognitive Domain. David McKay, New York.

Brown, Steve, Anne Clarke, and Ursula Frederick

2016 Object Stories: Artifacts and Archaeologists. Routledge, London.

Colaninno, Carol E.

2019 The Need for Discipline-Based Education Research in Archaeology. Journal of Archaeology and Education 3(7):1-24.

Crisp, Gloria, and Irene Cruz

2009 Mentoring College Students: A Critical Review of the Literature between 1990 and 2007. Research in Higher Education 50:525-545. DOI:10.1007/ s11162-009-9130-2.

Dixon, Kelly J.

2014 Historical Archaeologies of the American West. Journal of Archaeological Research 22:177-228.

Duncan, Jennifer

2020 Key Resources in Primary Sources \& Archival Resources. Electronic document, https://library2.usu.edu/inabs/result.php?SUBJECT=34\& Description=Primary + Sources $+\% 26$ amp\%3B + Archival+Resources, accessed November 10, 2020

Forest, Marion, Laurent Costa, Andy Combey, Antoine Dorison, and Grégory Pereira

2020 Testing Web Mapping and Active Learning to Approach Lidar Data. Advances in Archaeological Practice 8:25-39. DOI:10.1017/aap.2019.42.

Gamble, Lynn H., Cheryl Claassen, Jelmer W. Eerkens, Douglas J. Kennett, Patricia M. Lambert, Matthew J. Liebmann, and Torben C. Rick

2020 Finding Archaeological Relevance during a Pandemic and What Comes After. American Antiquity 86:1-21. DOI:10.1017/aaq.2020.94

Guillory, Raphael M., and Mimi Wolverton

2008 It's About Family: Native American Student Persistence in Higher Education. Journal of Higher Education 79:58-87. DOI:10.1080/00221546. 2008.11772086. 
Hanson, William S., and loana A. Oltean (editors)

2013 Archaeology from Historical Aerial and Satellite Archives. SpringerVerlag, New York.

Hein, Carola, Henk van Schaik, Diederik Six, Tino Mager, Jan (J. C. A.) Kolen, Maurits Ertsen, Steffen Nijhuis, and Gerdy Verschuure-Stuip

2020 Introduction: Connecting Water and Heritage for the Future. In Adaptive Strategies for Water Heritage, edited by Carola Hein, pp. 1-18. Springer, Cham, Switzerland

Holliday, Shastee

2020 Native American Summer Mentorship Program (@USU_NASMP) Tweeted: Here is Shastee Holliday's poster! \#NASMP2020. Twitter, June 8. https:// twitter.com/USU_NASMP/status/1270023246797172737, accessed April 7, 2021.

Janghorban, Roksana, Robab Latifnnejad Roudsari, and Ali Taghipour

2014 Skype Interviewing: The New Generation of Online Synchronous Interview in Qualitative Research. International Journal of Qualitative Studies on Health and Well-Being 9. DOI:10.3402/qhw.v9.24152.

Kefalis, Chrysovalantis, and Athanasios Drigas

2019 Web Based and Online Applications in STEM Education. International Journal of Engineering Pedagogy 9(4):76-85.

Keith, Jill. F., Sherri N. Stastny, and Ardith Brunt

2016 Barriers and Strategies for Success for American Indian College Students: A Review. Journal of College Student Development 57:698-714 Krathwohl, David R.

2002 A Revision of Bloom's Taxonomy: An Overview. Theory into Practice 41:212-218

Lin, Albert Yu-Min, Andrew Huynh, Gert Lanckriet, and Luke Barrington 2014 Crowdsourcing the Unknown: The Satellite Search for Genghis Khan. PLOS ONE 9(12):e114046. DOI:10.1371/journal.pone.0114046.

Little, Barbara J.

1991 Text-Aided Archaeology. CRC Press, Boca Raton, Florida.

Lupton, Deborah (editor)

2020 Doing Fieldwork in a Pandemic (crowd-sourced document). Electronic document, https://docs.google.com/document/d/1clGjGABB2h2qbdu TgfaribHmog9B6P0NvMgVuiHZCl8/edit?ts=5e88ae0a\#, accessed September 11, 2020.

Miller, Kathleen A.

2007 Climate Change and Water in the West: Complexities, Uncertainties and Strategies for Adaptation. Journal of Land, Resources \& Environmental Law 27:87-96

National Academies of Sciences, Engineering, and Medicine

2018 Graduate STEM Education for the 21st Century. National Academies Press, Washington, DC

2019 The Science of Effective Mentorship in STEMM. National Academies Press, Washington, DC

Navajo Nation COVID-19 Dashboard

2020 Navajo Nation COVID-19 Dashboard. Electronic document, https://www. ndoh.navajo-nsn.gov/COVID-19/Data, accessed November 10, 2020
O'Flaherty, Jacqueline, and Craig Phillips

2015 The Use of Flipped Classrooms in Higher Education: A Scoping Review. Internet and Higher Education 25:85-95.

Porcello, Darrell, and Sherry Hsi

2013 Crowdsourcing and Curating Online Education Resources. Science 341:240-241. DOI:10.1126/science.1234722.

Reddy, Y. Malini, and Heidi Andrade

2010 A Review of Rubric Use in Higher Education. Assessment \& Evaluation in Higher Education 35:435-448.

Rogers, Reenay R., and Yan Sun (editors)

2018 Engaging STEM Students from Rural Areas: Emerging Research and Opportunities. IGI Global, Hershey, Pennsylvania.

Shotton, Heather. J., E. Star L. Oosahwe, and Rosa Cintron

2007 Stories of Success: Experiences of American Indian Students in a PeerMentoring Retention Program. Review of Higher Education 31(1):81-107. DOI:10.1353/rhe.2007.0060.

Simms, Steven R., Tammy M. Rittenour, Chimalis Khuehn, and Molly Boeka Cannon

2020 Prehistoric Irrigation in Central Utah: Chronology, Agricultural Economics, and Implications. American Antiquity 85:452-469.

Simon, Nina

2014 Talking to Strangers: Building Shared Connections Around Unusual Objects. YouTube, March 5. https://youtu.be/zJG52QrLhFg, accessed April 7, 2021.

Smith, Linda Tuhwai

2012 Decolonizing Methodologies: Research and Indigenous Peoples. 2nd ed. Zed Books, London.

Tilley, Christopher, Webb Keane, Susanne Kuechler, Mike Rowlands, and Patricia Syper (editors)

2006 Handbook of Material Culture. SAGE, London.

USU Online

2020 Information about USU Online Programs. Electronic document, https:// www.usu.edu/online/about, accessed September 10, 2020.

Yates, Donna

2018 Crowdsourcing Antiquities Crime Fighting: A Review of Global Explorer Advances in Archaeological Practice 6:173-178. DOI:10.1017/aap.2018.8.

\section{AUTHOR INFORMATION}

Molly Boeka Cannon a Museum of Anthropology, Utah State University, 0730 Old Main Hill, Room 224, Logan, UT 84322, USA (molly.cannon@usu.edu, corresponding author)

Anna S. Cohen and Kelly N. Jimenez Anthropology Program, Utah State University, 0730 Old Main Hill, Room 224, Logan, UT 84322, USA 